\title{
LASER-INDUCED BREAKDOWN SPECTROSCOPY OF AL-SAMPLES: APPLICATION TO CHEMICAL ANALYSIS OF METALLIC ELEMENTS $f$
}

\author{
B. BESCÓS, J. CASTAÑO AND A. GONZÁLEZ UREÑA* \\ Unidad de Láseres y Haces Moleculares, Instituto Pluridisciplinar, Universidad \\ Complutense de Madrid, Juan XXIII-1 ${ }^{\circ}$, 28040-Madrid. Spain
}

(Received 3 March, 1994)

This paper reports on the simultaneous detection of $\mathrm{Mg}, \mathrm{Mn}, \mathrm{Fe}$ and $\mathrm{Pb}$ in $\mathrm{Al}$ samples using laser-induced breakdown spectroscopy and optical multichannel analysis of the photoablated microplasma. Using calibrated samples, well characterized linear working curves were determined for these minor components over the $0.01-1 \%$ concentration range. In addition optimum experimental conditions were found that allow the analysis to be carried out in a fast and non-invasive manner. The potential application of the method to on-line industrial analysis is also suggested.

KEY WORDS: Laser spectroscopy, chemical analysis photoablation, ablation.

\section{INTRODUCTION}

The advantages of laser ablation and/or desorption of solids in order to perform fast and simple chemical analysis is well known since the advent of the laser technology $^{1-3}$. Thus laser spectral microanalysis ${ }^{2}$ has become a current laboratory technique for rapid ${ }^{4-6}$, spot analysis of solid targets. Although very small amounts of solid material are typically vaporized, trace elements can be determined with concentration as low as a few ppm $^{6}$.

The present paper is dedicated to laser-induced ablation of aluminum samples and the subsequent analysis of trace elements by emission spectroscopy of the radiant plasma. Aluminum is a very important element in todays technology and trace element concentration in the pure metal and its alloys is of crucial importance for industrial applications. The present work is basically centered in the optimization of the detection conditions for $\mathrm{Mg}, \mathrm{Mn}, \mathrm{Fe}$ and $\mathrm{Pb}$ in Al-samples. Well characterized linear working-curves have been determined for the above elements over the $0.01-1 \%$

(f) This work received financial support from DGICYT of Spain, grant PB91/0357, and the Comunidad Autónoma de Madrid Research Programme.

(*) To whom correspondence should be addressed 
concentration range. Section I reports the experimental set up which is followed by the results in Section II. Finally in Section III these results are discussed together with the uses of the present method for on-line industrial applications.

\section{EXPERIMENTAL}

A schematic view of the experimental set up is shown in Figure 1. A Dye Laser (Continuum ND60) using Rhodamine 590 is pumped with the frequency-doubled $532 \mathrm{~nm}$ output of a Q-switched Nd:YAG Laser (Continuum ND81) giving pulse energies from 10 to $100 \mathrm{~mJ}$ at a frequency rate of $10 \mathrm{~Hz}$. The typical pulse energy used in the present work was about $45 \mathrm{~mJ}$.

A $4 \mathrm{~cm}$ focal-length lens was used to focus the laser onto the solid sample forming an incidence angle of 45 degrees with respect to the surface normal. The microplasma emission produced after laser ablation was collected at 90 degrees, with respect to the laser propagation direction, using an optical fibre coupled to an optical multichannel analyzer (OMA EG\&G 1461/88). The detector consisted of an intensified microchannel plate followed by a 1024 diode array. The detector is triggered by the laser pulse and typically operates with variable delay and gate detection times. Table I lists the most relevant experimental conditions.

Table I Typical experimental conditions
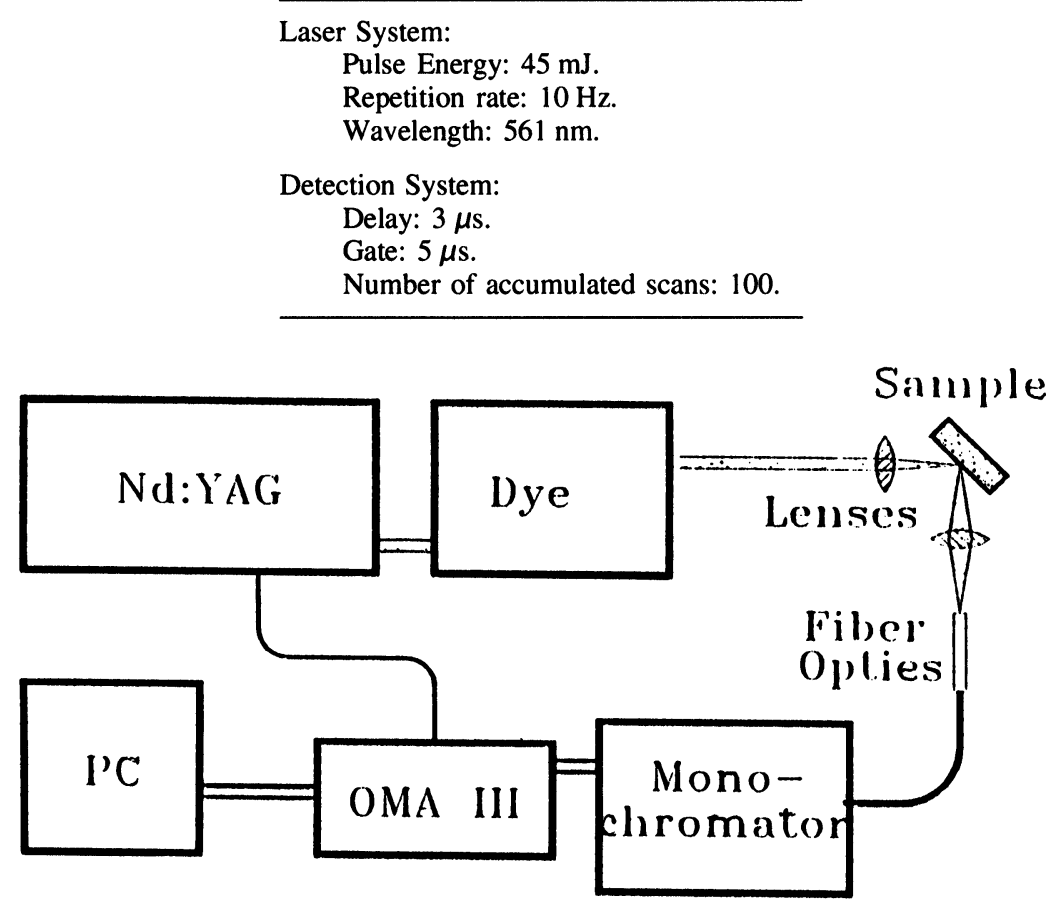

Figure 1 Schematic view of the experimental setup. 


\section{AL-SAMPLES}

For the present experiments we have used calibrated aluminum samples containing several metallic elements as displayed in Table II. The samples were provided and tested by Centro de Investigaciones Metalúrgicas (CENIM) of Madrid. In all the analyzed samples the major component was $\mathrm{Al}$.

Table II Concentration (in\%) of $\mathrm{Fe}, \mathrm{Mg}, \mathrm{Mn}$, and $\mathrm{Pb}$ in the calibrated aluminium samples

\begin{tabular}{llllll}
\hline Samples & $A$ & $B$ & $C$ & $D$ & $E$ \\
\hline $\mathrm{Fe}$ & .92 & .54 & .29 & .10 & 0.052 \\
$\mathrm{Mg}$ & .20 & .10 & .05 & .02 & 0.008 \\
$\mathrm{Mn}$ & .24 & .15 & .08 & .03 & 0.013 \\
$\mathrm{~Pb}$ & .16 & .10 & .05 & .02 & 0.010 \\
\hline
\end{tabular}

\section{RESULTS}

\section{Emission spectra}

Figure 2 displays the time evolution of the emission spectra over the $380-410 \mathrm{~nm}$ wavelength region. Notice the strong emission of $\mathrm{Al}$ at 394.40 and $396.15 \mathrm{~nm}$. In order to eliminate the strong plasma radiation we optimized the data collection using a $5 \mu \mathrm{s}$ gate after $3 \mu \mathrm{s}$ of delay. These conditions proved to be adequate for quantitative analysis.

Figure 3 shows a typical spectrum obtained using the B sample at atmospheric pressure. Table I summarizes the rest of experimental conditions. The range of wavelengths covered was $380-415 \mathrm{~nm}$. A clearer picture of the two $\mathrm{Al}$ lines around this region is shown in the inset. The atomic lines of $\mathrm{Mg}, \mathrm{Mn}, \mathrm{Fe}$ and $\mathrm{Pb}$ are also shown respectively at $383.83 \mathrm{~nm} ; 403.31 \mathrm{~nm} ; 404.58 \mathrm{~nm}$ and $405.78 \mathrm{~nm}$. To carry out a quantitative analysis of these metallic elements we have followed the suggestions from Ref. 1 and selected as reference emission the $394.40 \mathrm{~nm}$ line, which is far from the exciting wavelength to eliminate self-absorption processes. In addition we selected the already mentioned lines, close to the reference one, to minimize calibration errors.

\section{Quantitative analysis}

It has been shown that the intensity ratio of a spectral line emitted by a trace element (denoted i) to that emitted by the major constituent ( $j$ ) adopts the form ${ }^{3}$

$$
\frac{I_{i}}{I_{j}}=\frac{N_{i} g_{i} A_{i} Z_{j} \lambda_{j}}{N_{j} g_{j} A_{j} Z_{i} \lambda_{i}} \exp \left(-\frac{\Delta W}{k T_{e}}\right)
$$

where $\Delta \mathrm{W}=\mathrm{W}_{\mathrm{j}}-\mathrm{W}_{\mathrm{i}}$ and the rest of symbols as follows. $\mathrm{N}$, concentration; $\mathrm{g}$, degeneracy; A, Einstein coefficient for spontaneous emission; Z, partition function; 


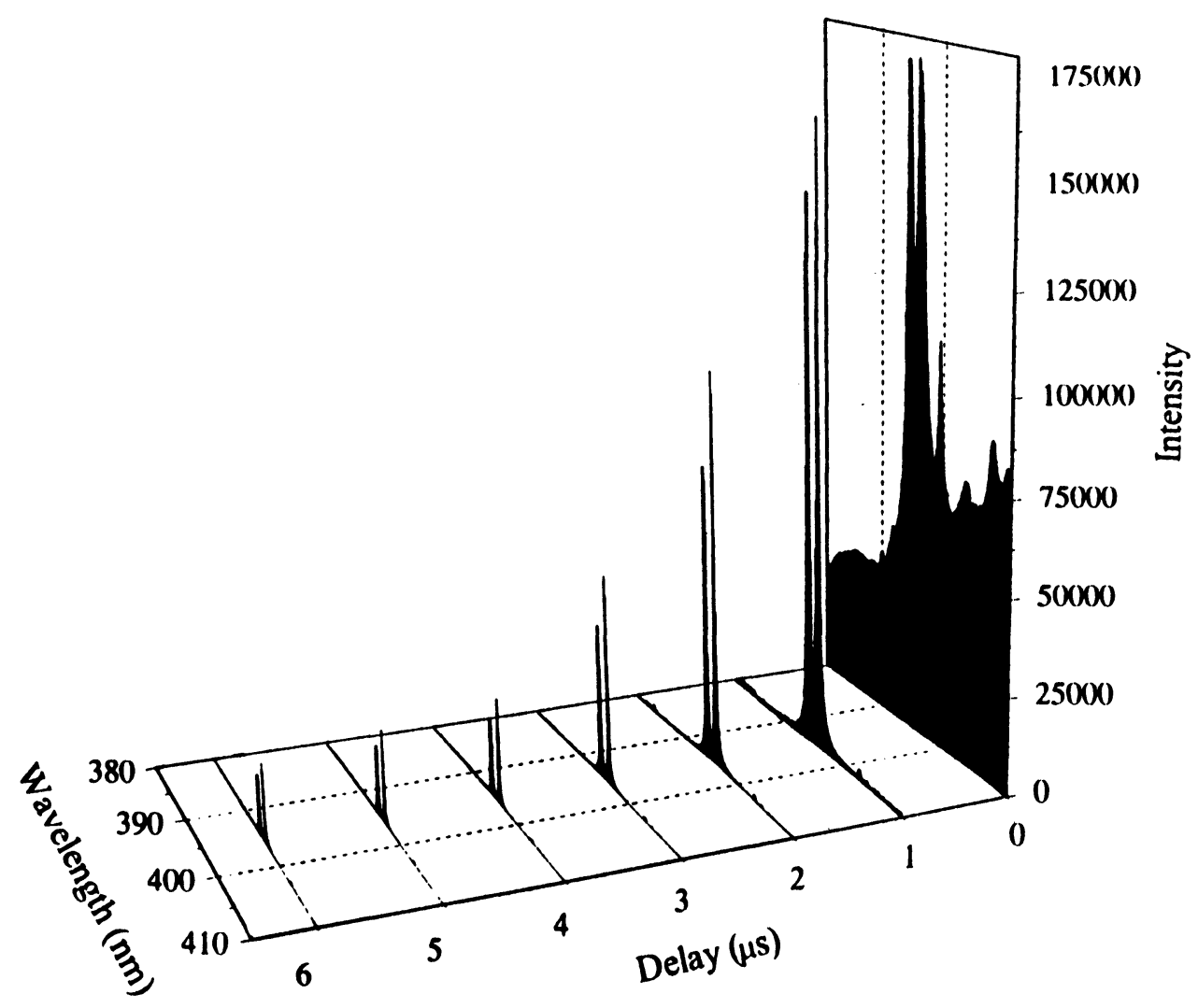

Figure 2 Time evolution of the emission spectra of an aluminium sample in the region of $380-410 \mathrm{~nm}$. Notice the strong peaks of $\mathrm{Al}$ at 394.40 and $396.15 \mathrm{~nm}$. Notice also the strong plama background emission at $0 \mu$ s of delay.

$\lambda$, wavelength of emitted photon, $\mathrm{W}_{\mathrm{i}}$, energy of a given state; $\mathrm{T}_{\mathrm{e}}$, electronic temperature.

Applying equation 1 to transitions with similar upper state energy the intensity ratio will only have a weak temperature dependence. Taking logarithms in (1) one obtains:

$$
\ln \frac{I_{i}}{I_{j}}=\ln \frac{N_{i}}{N_{j}}+\ln \left(\frac{g_{i} A_{i} Z_{j} \lambda_{j}}{g_{j} A_{j} Z_{i} \lambda_{i}}\right)-\frac{\Delta W}{k T_{e}}
$$

Thus, if the log of the intensity ratio is plotted against log of the fractional concentration of the trace element, a straight line, known as the working curve, will be obtained. Obviously, the concentration of an unknown sample can be obtained from such a curve deduced using samples of known concentration.

Figures 4, 5, 6 and 7 show the working curves for $\mathrm{Mg}, \mathrm{Mn}, \mathrm{Pb}$ and $\mathrm{Fe}$ respectively, obtained following equation 2 under the present experimental conditions. Analytical expressions for each working curve are shown in the insets. The slope values lower 


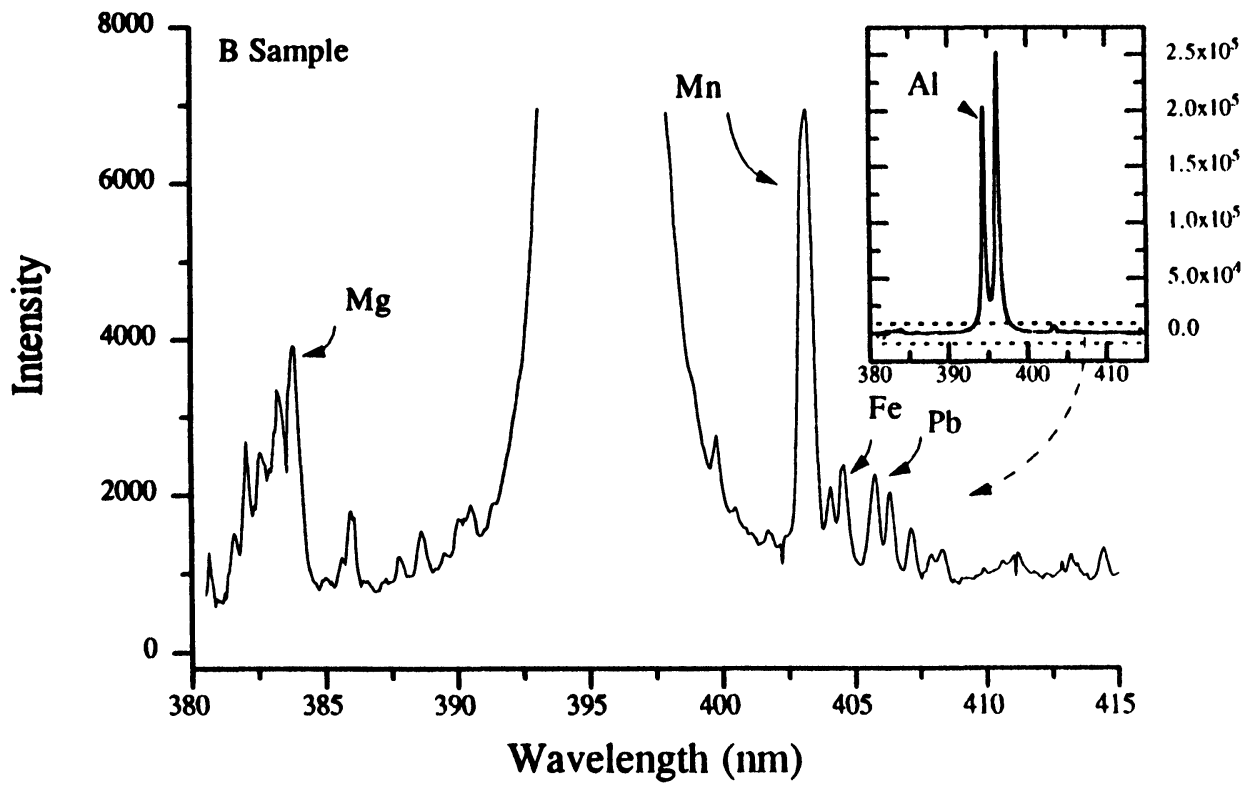

Figure 3 Typical spectrum of an aluminium sample in the region of $380-415 \mathrm{~nm}$, showing the peaks of the minor constituents. The aluminium lines in the same region are shown in the inset.

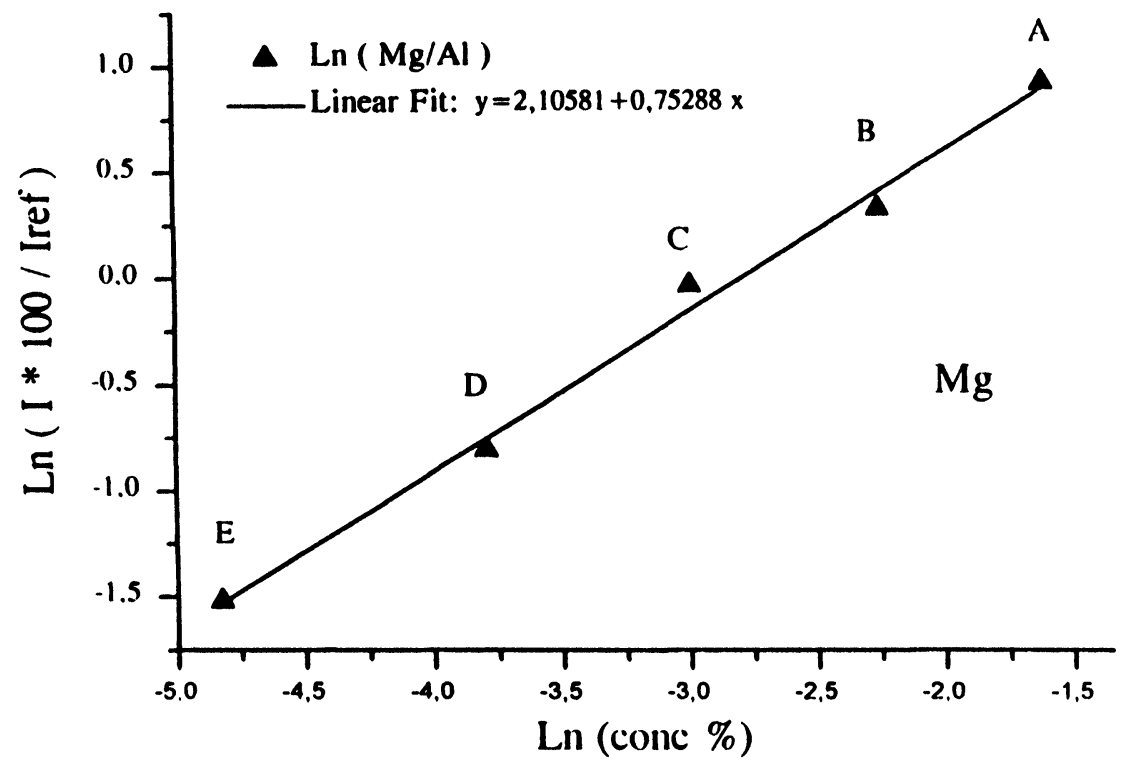

Figure 4 Working curve for $\mathrm{Mg}$ at $383.83 \mathrm{~nm}$ : Logarithmic plot of $100 *$ intensity ratio for magnesium/aluminium versus their concentration ratio. 


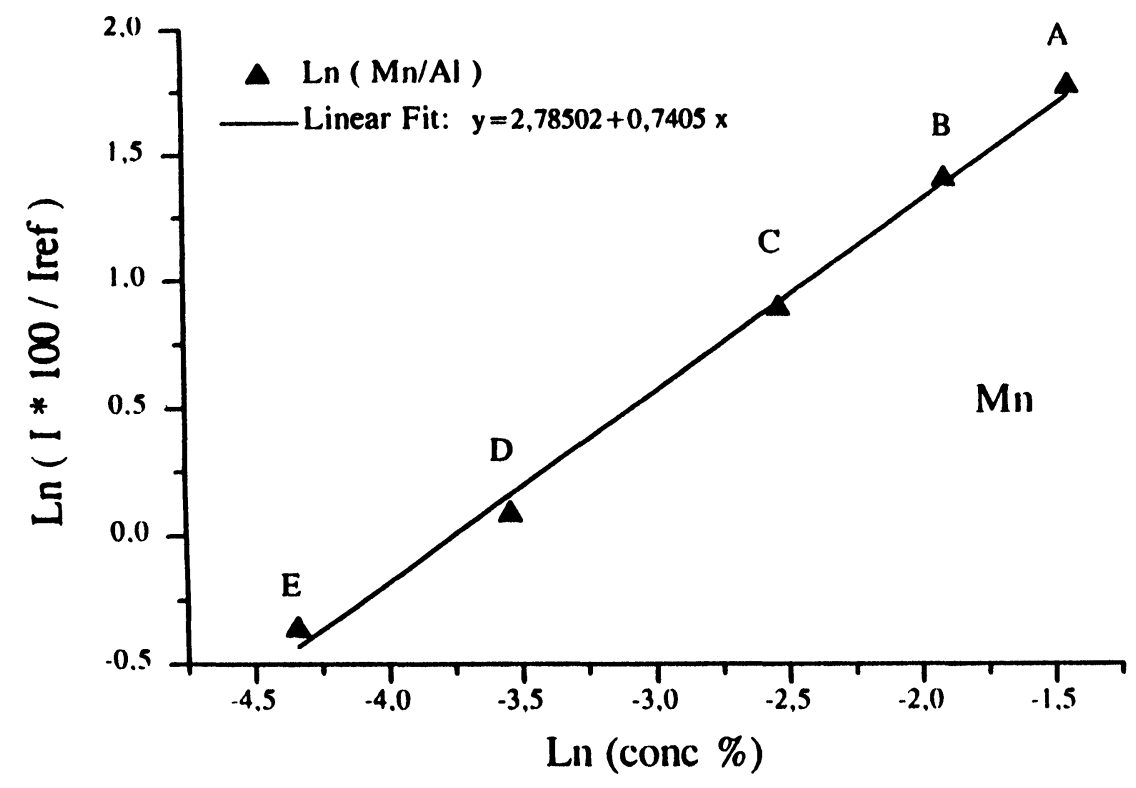

Figure 5 Working curve for $\mathrm{Mn}$ at $403.31 \mathrm{~nm}$.

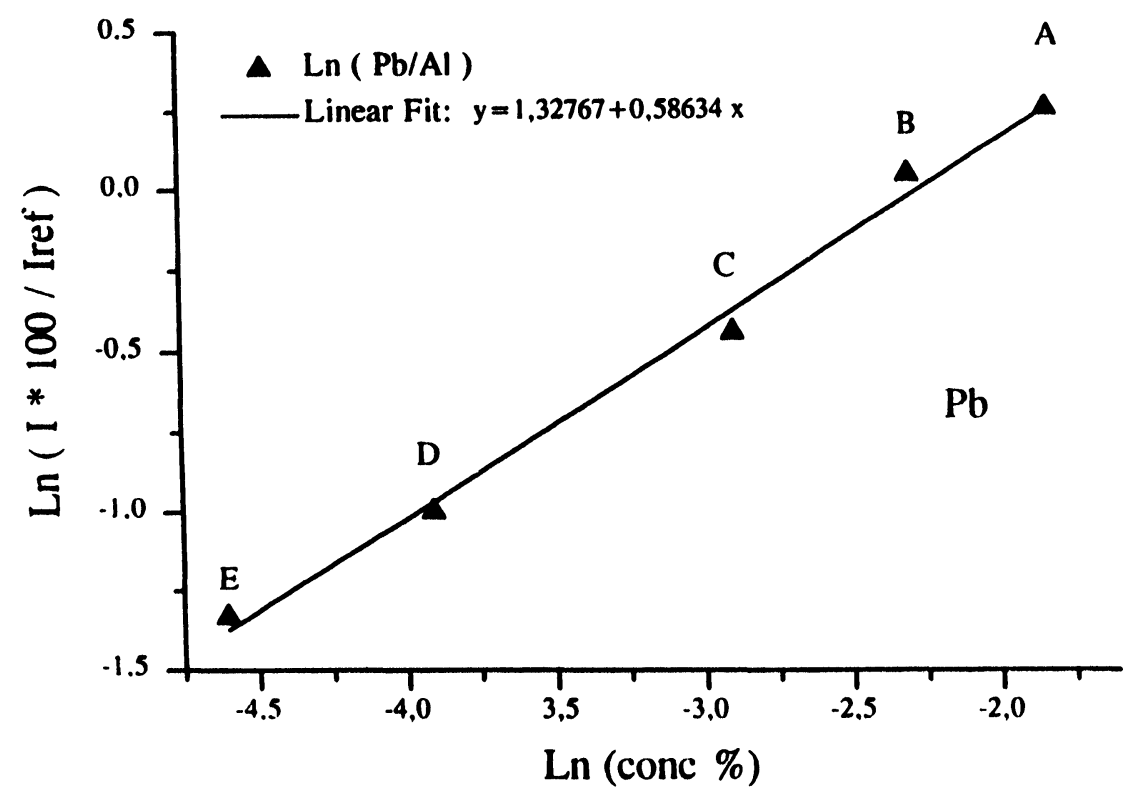

Figure 6 Working curve for $\mathrm{Pb}$ at $405.78 \mathrm{~nm}$. 


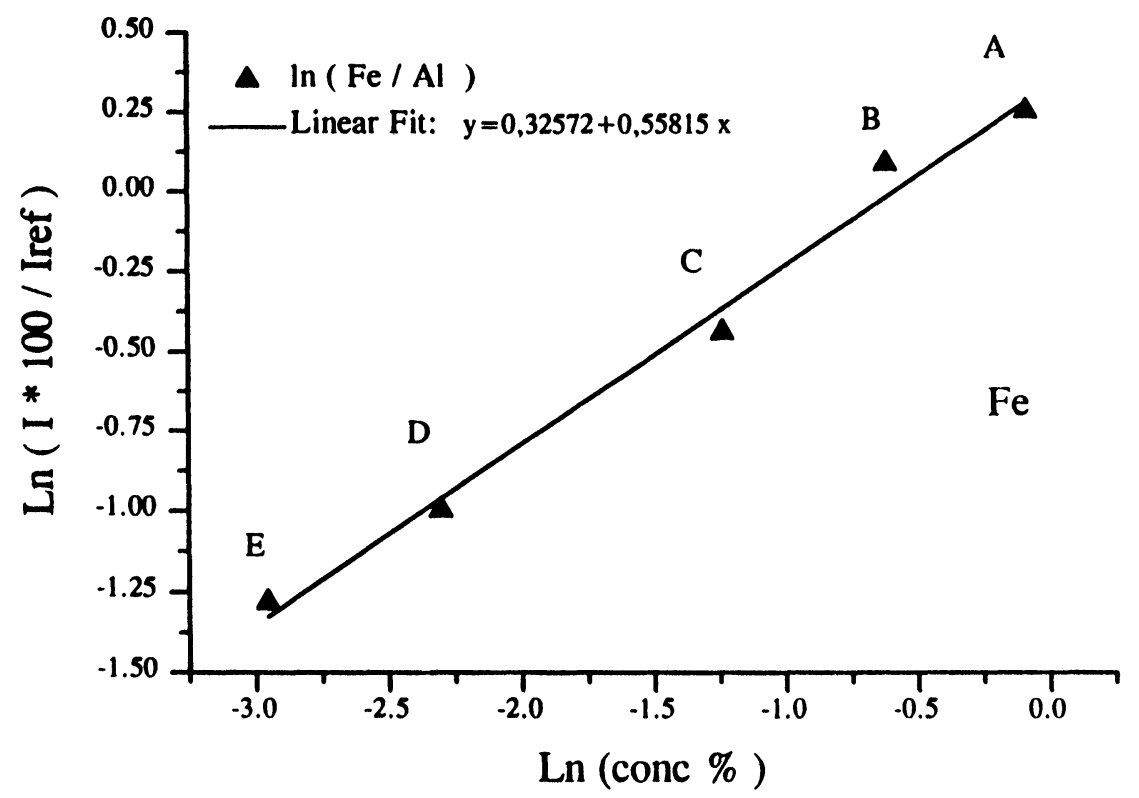

Figure 7 Working curve for $\mathrm{Fe}$ at $404.58 \mathrm{~nm}$.

than unity might be due to selective vaporization for one component with respect to other (matrix effect). Nevertheless, the major significance of the present results is the clear linearity of the experimentally obtained working curves, over the studied concentration range, ensuring their use for quantitative analysis.

\section{Concluding remarks}

This work has investigated and proved the feasibility of quantitative analysis of metallic trace elements in Al-samples using the laser ablation technique coupled to optical multichannel analysis of the microplasma emission. It has particularly focussed on the detection of $\mathrm{Mg}, \mathrm{Mn}, \mathrm{Fe}$ and $\mathrm{Pb}$ in an $\mathrm{Al}$ matrix over the $0,01-1 \%$ concentration range. One of the most significant aspects of the present work is the capability of quantitative analysis of trace elements as long as their emission line intensities could be normalized to those of major components. As a result, an intrinsic reference is provided for a direct, in situ, determination. Using calibrated samples, well characterized linear working-curves were determined for these minor elements, making possible their quantitative analysis. In addition optimum experimental conditions were found to implement their analysis in a fast and non-invasive manner. The fact that very little amount of material is vaporized together with the negligible size crater (ca. $100 \mu \mathrm{m}$ ) opens up its potential application to on-line industrial analysis. 


\section{References}

1. F. Brech and L. Cross. Appl. Spectrosc. 16, 59 (1962).

2. G. R. Kinsel, J. Linduer, J. Grotemeyer and W. Schlag. J. Phys. Chem., 95, 7824 (1991).

3. R. Tembreull and D. M. Lubman, Anal. Chem. 58, 1299 (1986).

4. See for example the review article by R. S. Adrain and J. Watson, J. Phys. D. Apply. Phys. 17, 1915 (1984).

5. D. R. Burges, Jr., I. Hussla, P. C. Stair, R. Viswanathan and E. Weitz, Rev. Sci. Instrum. 11, 1771 (1984).

6. M. A. Posthumus, P. G. Kistemaker, H. L. C. Meuzelaar and M. C. Ten Noever de Brauw, Anal. Chem. 50, 985 (1978).

7. S. M. Kimbrell and E. S. Yeung, Applied Spectroscopy 45, 442 (1991).

8. S. Mayo, T. B. Lucatorto and G. G. Luther. Anal. Chem. 54, 553 (1982). 